Article

\title{
Plantar Loads of Habitual Forefoot Strikers during Running on Different Overground Surfaces
}

\author{
Zhiwang Zhang ${ }^{\circledR}$, Yu Zhang, Weijie Fu ${ }^{\circledR}$, Zhen Wei, Jiayi Jiang and Lin Wang *(i) \\ School of Kinesiology, Shanghai University of Sport, Shanghai 200438, China; zhangzhiwang@sus.edu.cn (Z.Z.); \\ zhangyu20190801@yeah.net (Y.Z.); fuweijie@sus.edu.cn (W.F.); 1721518008@sus.edu.cn (Z.W.); \\ 1811517003@sus.edu.cn (J.J.) \\ * Correspondence: wanglin@sus.edu.cn; Tel.: +86-21-51253426
}

Received: 17 February 2020; Accepted: 25 March 2020; Published: 26 March 2020

check for updates

\begin{abstract}
The objective of this study is to investigate plantar loads characteristics of habitual forefoot strike runners while running on different surfaces. Twenty-six runners (age: $28.2 \pm 6.8 \mathrm{y}$, height: 172.9 $\pm 4.1 \mathrm{~cm}$, weight: $67.7 \pm 9.6 \mathrm{~kg}$, BMI (body mass index): $22.6 \pm 2.8 \mathrm{~kg} / \mathrm{m}^{2}$, running age: $5.0 \pm 4.2 \mathrm{y}$, running distance per week: $14.6 \pm 11.7 \mathrm{~km}$ ) with habitual forefoot strike participated in the study. Runners were instructed to run at $3.3 \pm 0.2 \mathrm{~m} / \mathrm{s}$ on three surfaces: grass, synthetic rubber and concrete. An in-shoe pressure measurement system was used to collect and analyze plantar loads data. Running on the synthetic rubber surface produced a lower plantar pressure in the lateral forefoot ( $256.73 \mathrm{kPa}$ vs. $281.35 \mathrm{kPa}, p=0.006$ ) than running on concrete. Compared with the concrete surface, lower pressure-time integrals were shown at the central forefoot (46.71 kPa.s vs. $50.73 \mathrm{kPa} \cdot \mathrm{s}, p=0.001)$ and lateral forefoot $(36.13 \mathrm{kPa} \cdot \mathrm{s}$ vs. $39.36 \mathrm{kPa} \cdot \mathrm{s}, p=0.004)$ when running on the synthetic rubber surface. The different surfaces influence plantar loads of habitual forefoot strikers and runners should choose appropriate overground surface to reduce the risk of lower extremity musculoskeletal injuries.
\end{abstract}

Keywords: forefoot strike pattern; plantar loads; sport injury

\section{Introduction}

Running is recognized for its health benefits and low cost as a popular exercise [1]. However, running is also related to a high risk of injuries rate varying from $19.4 \%$ to $79.3 \%$ at the lower limbs [2]. Many factors contributed to running injuries, such as shod conditions [3], training volume per week [4] and fatigue [5]. The overground surface is also an essential factor that has been studied in recent years [6,7]. Many investigators have identified the overground surface as an important variable that can affect load absorption mechanisms as revealed in the kinematics and kinetics of the lower limbs during running [7-10]. The accumulation of plantar loads could lead to chronic injuries when running for more than $64 \mathrm{~km}$ per week [2] and excessive plantar loads are considered to be a major cause of overuse running injuries [11,12]. Therefore, the overground surface plays an important part to prevent running injuries [4].

Different surfaces may be associated with different plantar loads, which may contribute to running injuries [13-15]. Compared to an asphalt surface, running on a natural grass surface has been shown to lower peak pressures at the lateral forefoot, lateral and central rearfoot [16]. Lower maximum pressure was observed on natural grass at the lateral forefoot, central forefoot, lateral midfoot and total foot compared to concrete surface [14]. Therefore, it might lower the risk of musculoskeletal injuries when running on grass surface rather than other surfaces like asphalt, concrete and synthetic rubber [14-16]. However, these different surfaces (synthetic, grass, concrete, and treadmill surfaces) did not change the pressure-time integral, the 1st and 2nd maximal plantar pressures and peak pressure distribution for habitual rearfoot strike pattern runners [13]. Overall, results comparing different overground surfaces 
may show lower plantar loads when running on a softer surface. However, inconsistent results have been discovered and the influence of different surfaces on plantar loads during running remains a contentious issue.

There are three strike patterns in the long-distance runners, namely rearfoot, midfoot and forefoot strikes [17]. Although the proportion of the forefoot strike pattern is small among runners [17,18], great attention has been paid to forefoot strike pattern in recent years because of the lower repetitive stress injury rate compared to rearfoot strikers $[19,20]$. The force-time integral, maximum force and contact area at the total foot were lower in forefoot strike pattern than rearfoot strike pattern [21]. In addition, the modification from rearfoot strike pattern to forefoot strike pattern can potentially prevent running injuries such as patellofemoral pain syndrome, exertional compartment syndrome $[3,19,22]$ and reduce pain and disability $[3,19,22]$. However, many studies on plantar loads characteristics of runners focus on rearfoot strike [23,24]. Although the contentious influence of different surfaces on plantar loads appears in the rearfoot striker, few studies exist regarding the plantar loads while running on different surfaces for runners with habitual forefoot strike [21,25].

Therefore, this current study aimed to examine plantar loads characteristics of habitual forefoot strike runners while running on grass $(G)$, concrete $(C)$ and synthetic rubber $(R)$ surfaces. Given that previous researchers identified a higher peak ground reaction force on a concrete surface than on an elastic surface [26], the hypothesis was that plantar loads during running on grass and synthetic rubber surface were lower than those during running on concrete surface.

\section{Materials and Methods}

\subsection{Participants}

Twenty-six male runners (age: $28.2 \pm 6.8$ y, height: $172.9 \pm 4.1 \mathrm{~cm}$, weight: $67.7 \pm 9.6 \mathrm{~kg}$, BMI: 22.6 $\pm 2.8 \mathrm{~kg} / \mathrm{m}^{2}$, running age: $5.0 \pm 4.2 \mathrm{y}$, running distance per week: $14.6 \pm 11.7 \mathrm{~km}$ ) with habitual forefoot strike were recruited in the study. All participants had self-reported running routine of more than $20 \mathrm{~km}$ per week. The dominant lower limb, which was confirmed as one's preferred leg using the way to kick a ball, was the right leg [27]. The exclusion criteria were as follows: reported cardiovascular diseases, surgery and musculoskeletal diseases in lower limbs over the past 6 months and other conditions (visual, vestibular and mental illnesses) that runner could not participant in this study. All participants gave their informed consent for inclusion before the trail. This study was approved by the Ethics Committee of Shanghai University of Sport (2018076).

\subsection{Running Surfaces}

Three different running surfaces were used artificial grass, concrete and synthetic rubber. The mechanical characteristics of the three surfaces were tested by measuring the index of ball rebound from American Society for Testing Materials (ASTM) standard [13]. The rebound height was calculated from five trials with a standard basketball (size 7\#) which was dropped vertically on each surface from a height of $2 \mathrm{~m}$ for each surface. The average rebound height from five trials for each surface indicated the surface hardness. The average heights were $102.7 \pm 0.8 \mathrm{~cm}$ (grass), $112.9 \pm 2.9 \mathrm{~cm}$ (concrete) and $131.5 \pm 1.4 \mathrm{~cm}$ (synthetic rubber). Each type of paved runway was $15 \mathrm{~m}$ long and $1 \mathrm{~m}$ wide, and the thickness of the synthetic rubber and grass was $2 \mathrm{~cm}$. The concrete runway was paved using concrete tiles with a thickness of $1 \mathrm{~cm}$. Each kind of surface was paved with polyvinyl chloride mattress $(1.6 \mathrm{~mm})$ to prevent the friction between running surface and floor.

\subsection{Data Acquisition}

This study was developed at the biomechanics laboratory in Shanghai University of Sport. All participants' body mass and height were measured. Data on self-reported strike pattern, age, running age and running distance per week were recorded. Running shoes (Sortiemagic $\operatorname{Rp} 4$ Tmm467-0790, European size 41 to 43, ASICS, Osaka, OSA, Japan) were distributed to each runner. 
Plantar loads data was collected using a Pedar-X system (Version 25.3.6e, Novel, Munich, Germany, 2009) with a sampling frequency of $100 \mathrm{~Hz}$. The thickness of each insole is $1.9 \mathrm{~mm}$ and the insoles were covered with soft artificial leather. The validity of the Pedar system has been demonstrated previously [28]. Pedar- $X$ was calibrated utilizing a standard device before the beginning of the protocol (Trublu Calibration, Version 25.3.6e, Novel, Munich, Germany, 2009) [14,23]. Before the formal test, participants' strike pattern at the target velocity $(3.3 \pm 0.2 \mathrm{~m} / \mathrm{s})$ [13] was verified using the Pedar-X system and by calculating the centre of pressure (COP) to verify the participants' strike pattern. If COP was anterior to $33 \%$ of foot length at initial loading contact at the speed of $3.3 \pm 0.2 \mathrm{~m} / \mathrm{s}[29,30]$, the foot striking pattern was confirmed as a forefoot strike. In addition, each participant ran on a treadmill for $5 \mathrm{~min}$ to warm up at their preferred speeds. After the warm-up, participants practiced in order to become comfortable to the three different surfaces and to adjust their running speed to the one requested $(3.3 \pm 0.2 \mathrm{~m} / \mathrm{s})$.

The protocol consisted of running at the target velocity $(3.3 \pm 0.2 \mathrm{~m} / \mathrm{s})$ on each of the three $15-\mathrm{m}$ runway surface for three times. The order of the three different running surfaces was randomised for each participant. The target running velocity of $3.3 \pm 0.2 \% \mathrm{~m} / \mathrm{s}$ was chosen to reduce the impact of running speed on the plantar pressure [13]. During the test, the running velocity was controlled by a 3-m photoelectric timing system (WittySEM, Microgate, Bolzano, Italy) which was placed in the middle of the 15-m runway. A high-speed video camera (MotionPro X-4, Integrated Design Tools Inc., Pasadena, CA, USA) at a sampling rate of $100 \mathrm{~Hz}$ was used to record the steps of the participants and confirm that the right foot fell within the 3-m measurement zone of the photoelectric timing system (WittySEM, Microgate, Bolzano, Italy). When the camera captured a turning-on flash of Pedar-X system, the data collection began. A total of nine valid trials were collected, with three per each running surface. A running repetition was considered valid if the right foot fell within the $3 \mathrm{~m}$ measurement zone of the speed controlled machine (WittySEM, Microgate, Bolzano, Italy) and the running speed was within $3.3 \pm 0.2 \mathrm{~m} / \mathrm{s}$, otherwise the trial was repeated.

\subsection{Data Reduction}

The plantar loads data under the right foot were analysed by the multimask evaluation (Novel Multimask, Version 25.3.6e, Novel, Munich, Germany, 2013). The right foot was divided into nine regions as shown in Figure 1. This division was consistent with previous studies [14,23]. During the stance phase, Peak pressure (PP), maximum force (MF), contact area (CA), pressure-time integral (PTI) and force-time integral integral (FTI) for the total foot and for each of the nine selected areas were calculated. PP is the maximum pressure of the foot, MF is maximum impact force of the foot, CA is the maximum area of the foot, PTI is the integration of plantar pressure over time of the foot, FTI is the integration of plantar force over time of the foot. FTI and MF were normalized by the body weight of each participant.

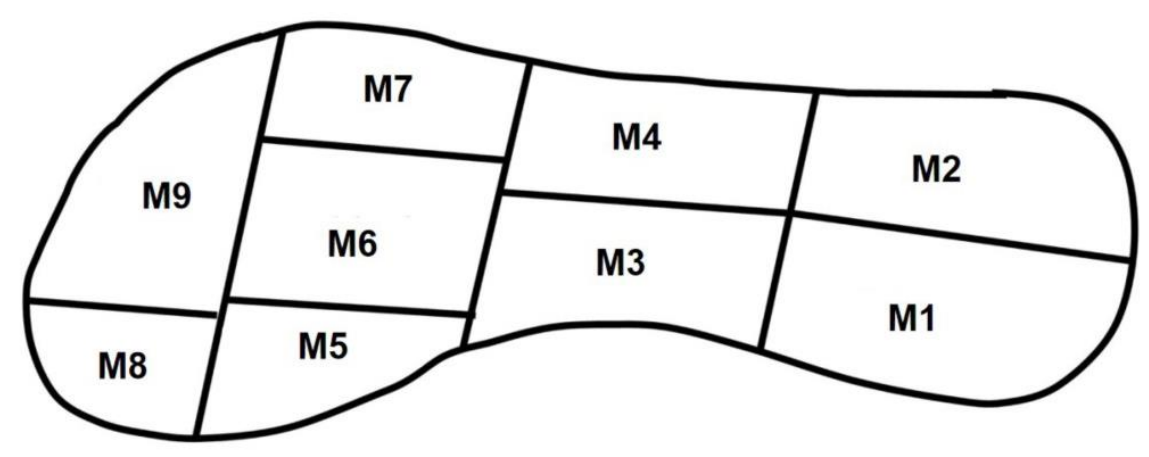

Figure 1. Insole masks. M1 (medial heel), M2 (lateral heel), M3 (medial midfoot), M4 (lateral midfoot), M5 (medial forefoot), M6 (central forefoot), M7 (lateral forefoot), M8 (great toe), and M9 (lesser toes). 


\subsection{Statistical Analysis}

The Shapiro-Wilk test was performed to test data normal distribution and Levene's test was used to check homoscedasticity. The data of plantar loads were normally distributed and therefore parametric tests were implemented. A one-way variance analysis of repeated measurements was used to assess the data of the three surfaces on plantar loads and a Bonferonni post-hoc test was performed for further multiple comparisons A 95\% confidence interval (CI) was also calculated for the multiple comparisons. The significance level was set at $\alpha<0.05$. The statistics were executed using SPSS software (Version 20.0, IBM Corp, Armonk, NY, USA,2011).

\section{Results}

The plantar loads express in terms of peak pressure, maximum force, contact area, pressure-time integral and force-time integral integral for the total foot and for each of the nine plantar regions are presented in Table 1.

Table 1. Comparison of Plantar Loads between Different Surfaces.

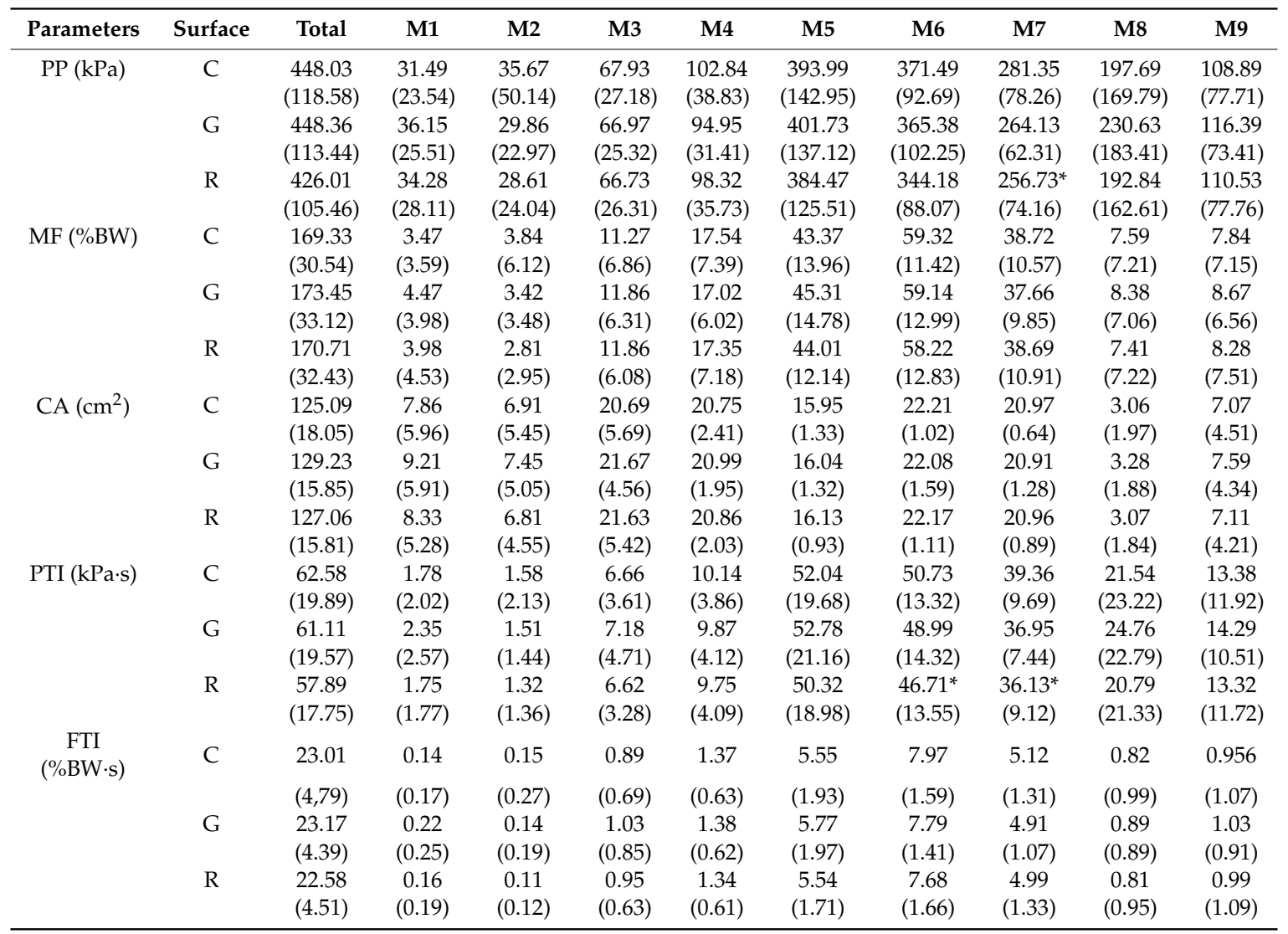

All data were means and standard deviation (SD). PP, peak pressure; MF, maximum force; CA, contact area; PTI, pressure-time integral; FTI, force-time integral integral; M1, medial heel; M2, lateral heel; M3, medial midfoot; M4, lateral midfoot; M5, medial forefoot; M6, central forefoot; M7, lateral forefoot; M8, great toe; M9, lesser toes. C, concrete; G, grass; $\mathrm{R}$, synthetic rubber; ${ }^{*}$ Significant differences $(p<0.05)$ between rubber surface and concrete surface.

The analysis of variance (ANOVA) demonstrated difference in PP among the different surfaces in lateral forefoot $[\mathrm{F}(2,50)=6.523, p=0.003]$. The Bonferonni post-hoc test showed that running on synthetic rubber revealed lower plantar pressure on the lateral forefoot $(p=0.006,95 \% \mathrm{CI}=6.41$ to $42.94 \mathrm{kPa}$ ) than running on concrete (Table 1). No significant differences were showed in PP at this region between grass and rubber and between grass and concrete. No significant differences were observed in PP for the total foot and for the other regions between the three surfaces. 
In terms of MF and CA, no significant differences were found for the total foot and for each of nine foot regions between the three surfaces in Table 1.

Differences were found in PTI for the central forefoot $[\mathrm{F}(2,50)=5.713, p=0.006]$ and lateral forefoot $[\mathrm{F}(2,50)=4.707, p=0.013]$. Running on concrete revealed higher PTIs on the central forefoot $(p=0.001,95 \% \mathrm{CI}=1.13$ to $6.92 \mathrm{kPa} \cdot \mathrm{s})$ and lateral forefoot $(p=0.004,95 \% \mathrm{CI}=1.53$ to $5.01 \mathrm{kPa} \cdot \mathrm{s})$ than running on synthetic rubber surface in the post hoc test. No significant differences were found in PTIs for synthetic rubber at central and lateral forefoot regions when compared to grass surfaces or concrete surfaces. No significant differences were found in PTIs for the total foot and for the other regions between the three surfaces.

No significant differences were observed in FTI for the total foot and for all nine foot regions between the three surfaces in Table 1.

\section{Discussion}

This study examined the influence of surfaces on plantar loads among runners with habitual forefoot strike. The hypothesis in the current study was that lower plantar loads would be found on rubber and grass surfaces when compared with the loads on concrete surface. Our hypothesis was partially supported because running on synthetic rubber showed significantly lower plantar pressure in lateral forefoot and lower pressure-time integral in central forefoot and lateral forefoot when compared to running on concrete. However, no differences were found in plantar pressure and pressure-time integral for grass surface compared to synthetic rubber or concrete. No differences were found for maximum force, contact area, and force-time integral integral while runners run on the three surfaces.

In the current study, there were significant different plantar loads on the lateral and central forefoot when participants were running at the target velocity of $3.3 \pm 0.2 \mathrm{~m} / \mathrm{s}$ on synthetic rubber and concrete surfaces. Direct comparison with other studies was unreasonable, as there were few studies on plantar loads with forefoot strike pattern. Although the participants performed running on a forefoot strike pattern and significant difference of PTI in forefoot area was also found in a previous study [31], the participants ran with regular rearfoot strike pattern before participating in the trail. In a previous study, significantly different plantar loads were presented on the lateral and central forefoot [23]. However, the surfaces (natural grass, treadmill and concrete) and running speed $(3.8 \mathrm{~m} / \mathrm{s}$ ) used in the study [23] were not exactly the same as these in the current study. Although similar plantar loads were showed in an investigation into different strike patterns at the same running speed $(3.3 \mathrm{~m} / \mathrm{s})$ in another study [21], the data were only collected in synthetic rubber surface. Although the plantar loads of nonrearfoot strikers during running were investigated in a previous study [32], the study aimed to compare the plantar loading of rearfoot strikers and nonrearfoot strikers after receiving a 4-week running program with minimalist footwear instead of overground surfaces. In addition, the current results are in line with a previous study that showed different impact absorbing ability comparing overground surfaces [14,23], although different strike patterns (rearfoot and forefoot) were tested in these previous studies. However, a study found that four different surfaces (grass, concrete, synthetic track and treadmill) had no significant effect on PP and PTI under the same running speed $(12 \mathrm{~km} / \mathrm{h})$ [13]. Differences between the current work and the previous study [13] could be attributed to different effects of foot striking pattern (forefoot strike vs. rearfoot strike) on plantar loads distribution [21], different cushioning of foot wear (Shanghong Shoes Co. Ltd., Shanghai, China vs. ASICS, Osaka, OSA, Japan) [33], and different insole measuring devices (Version 4.4; T\&T Medilogic Medizintechnik GmbH, Schönefeld, Germany vs. Version 25.3.6e, Novel, Munich, Germany, 2009) for plantar regional division [28].

It has been shown previously that running on different overground surfaces produces significant differences in plantar loads $[14,23,31]$. However, the participants in these previous studies were rearfoot strikers, which has larger plantar loads during the stance phase when compared with forefoot strike pattern. In the current study, the plantar loads were tested in habitual forefoot strikers and no significant differences were found on total foot. These findings were consistent with a previous 
study [3], confirming that the lower limbs can show similar loading rate with a forefoot strike pattern between barefoot and shod conditions. This study therefore indicates that the lower limbs can show more compliance with a forefoot strike pattern during running on different overground surfaces.

Higher and repetitive plantar loading might play a risk factor leading to forefoot injuries [34]. When running on concrete surfaces for repetitive and long-distance training, a high peak pressure might load excessive stress on the human skeletal musculature. Previous investigators have shown that metatarsal stress fractures accounted for $14 \%$ to $18 \%$ of all stress fractures in high-impact sports involving jumping and running [35,36]. Approximately $80 \%$ of these fractures were found in the second and third metatarsals in the forefoot [37]. Therefore, results of the current study are in line with the literature, suggesting that concrete surfaces might have a greater potential to increase the risk of diseases of musculoskeletal system caused by overuse and lead to sports injury in runners under higher forefoot loads when comparing running on the synthetic rubber surface.

In the current study, peak pressure and pressure-time integral showed differences between concrete and synthetic rubber; however, no significant difference was found in the same parameters comparing running on grass and concrete surfaces or grass and synthetic rubber surfaces. The grass surface did not perform like a compliant surface and the result was different from several studies which showed that the grass surface could reduce lower plantar loads when running in different surfaces $[14,16,23]$. This finding was possible because the impact of the grass surface, which was artificial in the current study, might differ from that of the natural grass surface. The average rebound height of grass surface $(102.7 \pm 0.8 \mathrm{~cm})$ in the current study is also close to that in concrete surface $(112.9 \pm 2.9 \mathrm{~cm})$. When football players trained on artificial ground, the anterior cruciate ligament injuries were more than that on natural grass [38] and the peak force on artificial turf in is higher than that on natural grass during running [39]. Therefore, instead of a artificial grass surface, a natural grass surface should be considered to reduce the incidence of sport injuries lower limbs [40].

Maximal forces and force-time integral integral did not show significant differences between the three surfaces running at $3.3 \pm 0.2 \mathrm{~m} / \mathrm{s}$. Similarly to Wang et al. [14], no statistical differences were found in maximal force while running on grass surfaces, concrete and synthetic rubber, though the participant were rearfoot strike pattern in their study. Regardless of the strike pattern used while running, runners might compensate for different ground surfaces loads to protect themselves from injury [13]. Ferris et al. [41] found human runners could change leg stiffness when loading on different surfaces and keep similar contact time, stride frequency, and peak vertical ground reaction force during running on all of the surfaces.

The running surfaces used in the present study did not result in significant differences in the contact area when running. This finding is similar to that of Wang et al. [14], although the participants in their study were habitual rearfoot strike pattern runners. However, Tessutti et al. [15] reported that contact area on a grass surface was significantly greater at the central rearfoot compared with that contact area asphalt surface. The use of a different number of region divisions ( 9 in current study vs. 6 in the study of Tessutti et al.) in the foot, different surfaces (grass, concrete and synthetic rubber in current study vs. grass and asphalt in the study of Tessutti et al.) likely led to the differences between present findings and those of Tessutti et al. [15].

Previous researchers have reported that the peak loading rates in each direction (3D resultant, vertical, mediolateral and anterior-posterior directions) were influenced by the foot strike pattern of runners [42]. A previous study found that the nonrearfoot group showed a visible impact peak in the anteroposterior and mediolateral ground reaction force [43]. In the current study, three-dimensional plantar loads were not investigated because the Pedar-X system allows showing only vertical direction; therefore, further research on three-dimensional loads during forefoot running is needed. However, the present study provides evidence that a synthetic rubber surface is more appropriate for runners to prevent running injuries and further work should explore the effect of different overground surfaces on plantar loads in 3D resultant and vertical, mediolateral and anterior-posterior directions. This study has several limitations. Firstly, although the participants' foot strike pattern was affirmed as the same 
way some previous studies presented $[29,30]$ and the insole mask was used following the method described in previous studies $[14,23]$, some data in heel seemed to vary widely and variation might be caused by the slight backward movement of centre of planter pressure after forefoot contacting the ground [30]. Secondly, the experiment was carried out in a laboratory, which was different from the real running environment. Such difference might lead to some difficulties in reflecting a real situation.

\section{Conclusions}

The findings of the current study show the different effect of overground surfaces on plantar loads during running among habitual forefoot strike runners. The current study indicates that the synthetic rubber surface used in running can help to reduce plantar loads on the forefoot for habitual forefoot strike pattern runners when compared to running on concrete. Therefore, runners should choose a synthetic rubber surface to attenuate overloads on the musculoskeletal system and reduce the risk of musculoskeletal injuries in the lower extremity.

Author Contributions: Conceptualization, L.W. and Z.Z.; methodology, L.W., Y.Z., J.J. and Z.Z.; software, Z.W. and W.F.; validation, Z.W., W.F. and Z.Z.; formal analysis, Z.Z.; investigation, Y.Z., and J.J.; resources, Y.Z., and J.J.; data curation, Z.Z. and Z.W.; writing-original draft preparation, Z.Z.; writing-review and editing, L.W. and Z.W.; supervision, L.W.; project administration, L.W.; funding acquisition, L.W. All authors have read and agreed to the published version of the manuscript.

Funding: This work was funded by the National Natural Science Foundation of China (11572202, 11772201 and 31700815).

Conflicts of Interest: The authors declare no conflicts of interest.

\section{References}

1. Novacheck, T.F. The biomechanics of running. Gait Posture 1998, 7, 77-95. [CrossRef]

2. van Gent, R.N.; Siem, D.; van Middelkoop, M.; van Os, A.G.; Bierma-Zeinstra, S.M.; Koes, B.W. Incidence and determinants of lower extremity running injuries in long distance runners: A systematic review. Br. J. Sports Med. 2007, 41, 469-480. [CrossRef]

3. Shih, Y.; Lin, K.L.; Shiang, T.Y. Is the foot striking pattern more important than barefoot or shod conditions in running? Gait Posture 2013, 38, 490-494. [CrossRef]

4. Van der Worp, M.P.; ten Haaf, D.S.; van Cingel, R.; de Wijer, A.; Nijhuis-van der Sanden, M.W.; Staal, J.B. Injuries in runners; a systematic review on risk factors and sex differences. PLoS ONE 2015, 10, e0114937. [CrossRef]

5. Schutte, K.H.; Seerden, S.; Venter, R.; Vanwanseele, B. Influence of outdoor running fatigue and medial tibial stress syndrome on accelerometer-based loading and stability. Gait Posture 2018, 59, 222-228. [CrossRef] [PubMed]

6. Hollis, C.R.; Koldenhoven, R.M.; Resch, J.E.; Hertel, J. Running biomechanics as measured by wearable sensors: Effects of speed and surface. Sports Biomech. 2019, 1-11. [CrossRef]

7. Dixon, S.J.; Collop, A.C.; Batt, M.E. Surface effects on ground reaction forces and lower extremity kinematics in running. Med. Sci. Sports Exerc. 2000, 32, 1919-1926. [CrossRef]

8. Willwacher, S.; Fischer, K.M.; Rohr, E.; Trudeau, M.B.; Hamill, J.; Bruggemann, G.P. Surface stiffness and footwear affect the loading stimulus for lower extremity muscles when running. J. Strength Cond. Res. 2020. [CrossRef]

9. Gantz, A.M.; Derrick, T.R. Kinematics and metabolic cost of running on an irregular treadmill surface. J. Sports Sci. 2018, 36, 1103-1110. [CrossRef]

10. Huang, L.; Liu, Y.; Wei, S.; Li, L.; Fu, W.; Sun, Y.; Feng, Y. Segment-interaction and its relevance to the control of movement during sprinting. J. Biomech. 2013, 46, 2018-2023. [CrossRef]

11. Hreljac, A. Impact and overuse injuries in runners. Med. Sci. Sports Exerc. 2004, 36, 845-849. [CrossRef] [PubMed]

12. Mann, R.; Malisoux, L.; Urhausen, A.; Meijer, K.; Theisen, D. Plantar pressure measurements and running-related injury: A systematic review of methods and possible associations. Gait Posture 2016, 47, 1-9. [CrossRef] [PubMed] 
13. Fu, W.J.; Fang, Y.; Liu, D.M.S.; Wang, L.; Ren, S.C.; Liu, Y. Surface effects on in-shoe plantar pressure and tibial impact during running. J. Sport Health Sci. 2015, 4, 384-390. [CrossRef]

14. Wang, L.; Hong, Y.; Li, J.X.; Zhou, J.H. Comparison of plantar loads during running on different overground surfaces. Res. Sports Med. 2012, 20, 75-85. [CrossRef]

15. Tessutti, V.; Ribeiro, A.P.; Trombini-Souza, F.; Sacco, I.C. Attenuation of foot pressure during running on four different surfaces: Asphalt, concrete, rubber, and natural grass. J. Sports Sci. 2012, 30, 1545-1550. [CrossRef]

16. Tessutti, V.; Trombini-Souza, F.; Ribeiro, A.P.; Nunes, A.L.; Sacco Ide, C. In-shoe plantar pressure distribution during running on natural grass and asphalt in recreational runners. J. Sci. Med. Sport 2010, 13, 151-155. [CrossRef]

17. Larson, P.; Higgins, E.; Kaminski, J.; Decker, T.; Preble, J.; Lyons, D.; Mcintyre, K.; Normile, A. Foot strike patterns of recreational and sub-elite runners in a long-distance road race. J. Sports Sci. 2011, 29, 1665-1673. [CrossRef]

18. Kasmer, M.E.; Liu, X.C.; Roberts, K.G.; Valadao, J.M. Foot-strike pattern and performance in a marathon. Int. J. Sports Physiol. Perform. 2013, 8, 286-292. [CrossRef]

19. Cheung, R.T.; Davis, I.S. Landing pattern modification to improve patellofemoral pain in runners: A case series. J. Orthop. Sports Phys. Ther. 2011, 41, 914-919. [CrossRef]

20. Milner, C.E.; Ferber, R.; Pollard, C.D.; Hamill, J.; Davis, I.S. Biomechanical factors associated with tibial stress fracture in female runners. Med. Sci. Sports Exerc. 2006, 38, 323-328. [CrossRef]

21. Wei, Z.; Zhang, Z.; Jiang, J.; Zhang, Y.; Wang, L. Comparison of plantar loads among runners with different strike patterns. J. Sports Sci. 2019, 37, 2152-2158. [CrossRef] [PubMed]

22. Diebal, A.R.; Gregory, R.; Alitz, C.; Gerber, J.P. Forefoot running improves pain and disability associated with chronic exertional compartment syndrome. Am. J. Sports Med. 2012, 40, 1060-1067. [CrossRef] [PubMed]

23. Hong, Y.; Wang, L.; Li, J.X.; Zhou, J.H. Comparison of plantar loads during treadmill and overground running. J. Sci. Med. Sport 2012, 15, 554-560. [CrossRef] [PubMed]

24. Sterzing, T.; Frommhold, C.; Rosenbaum, D. In-shoe plantar pressure distribution and lower extremity muscle activity patterns of backward compared to forward running on a treadmill. Gait Posture 2016, 46, 135-141. [CrossRef] [PubMed]

25. Garcia-Perez, J.A.; Perez-Soriano, P.; Llana, S.; Martinez-Nova, A.; Sanchez-Zuriaga, D. Effect of overground vs treadmill running on plantar pressure: Influence of fatigue. Gait Posture 2013, 38, 929-933. [CrossRef]

26. Fritz, M.; Peikenkamp, K. Simulation of the influence of sports surfaces on vertical ground reaction forces during landing. Med Boil. Eng. 2003, 41, 11-17. [CrossRef]

27. Ghena, D.R.; Kurth, A.L.; Thomas, M.; Mayhew, J. Torque characteristics of the quadriceps and hamstring muscles during concentric and eccentric loading. J. Orthop. Sports Phys. Ther. 1991, 14, 149-154.

28. Price, C.; Parker, D.; Nester, C. Validity and repeatability of three in-shoe pressure measurement systems. Gait Posture 2016, 46, 69-74. [CrossRef]

29. Vannatta, C.N.; Kernozek, T.W. Patellofemoral joint stress during running with alterations in foot strike pattern. Med. Sci. Sports Exerc. 2015, 47, 1001-1008. [CrossRef]

30. Altman, A.R.; Davis, I.S. A kinematic method for footstrike pattern detection in barefoot and shod runners. Gait Posture 2012, 35, 298-300. [CrossRef]

31. Sun, X.; Yang, Y.; Wang, L.; Zhang, X.; Fu, W. Do strike patterns or shoe conditions have a predominant influence on foot loading? J. Hum. Kinet. 2018, 64, 13-23. [CrossRef]

32. Kernozek, T.W.; Meardon, S.; Vannatta, C.N. In-shoe loading in rearfoot and non-rearfoot strikers during running using minimalist footwear. Int. J. Sports Med. 2014, 35, 1112-1117. [CrossRef] [PubMed]

33. Wiegerinck, J.I.; Boyd, J.; Yoder, J.C.; Abbey, A.N.; Nunley, J.A.; Queen, R.M. Differences in plantar loading between training shoes and racing flats at a self-selected running speed. Gait Posture 2009, 29, 514-519. [CrossRef] [PubMed]

34. Hockenbury, R.T. Forefoot problems in athletes. Med. Sci. Sports Exerc. 1999, 31, S448-S458. [CrossRef] [PubMed]

35. Kiuru, M.J.; Niva, M.; Reponen, A.; Pihlajamaki, H.K. Bone stress injuries in asymptomatic elite recruits: A clinical and magnetic resonance imaging study. Am. J. Sports Med. 2005, 33, 272-276. [CrossRef] [PubMed]

36. Brukner, P.; Bradshaw, C.; Khan, K.M.; White, S.; Crossley, K. Stress fractures: A review of 180 cases. Clin. J. Sport Med. 1996, 6, 85-89. [CrossRef] [PubMed] 
37. Fetzer, G.B.; Wright, R.W. Metatarsal shaft fractures and fractures of the proximal fifth metatarsal. Clin. Sports Med. 2006, 25, 139-150. [CrossRef]

38. Dragoo, J.L.; Braun, H.J.; Harris, A.H.S. The effect of playing surface on the incidence of acl injuries in national collegiate athletic association American football. Knee 2013, 20, 191-195. [CrossRef]

39. McMurtry, S.; Fiedler, G. Comparison of lower limb segment forces during running on artificial turf and natural grass. J. Rehabil. Assist. Technol. Eng. 2019, 6, 1-5. [CrossRef]

40. Loughran, G.J.; Vulpis, C.T.; Murphy, J.P.; Weiner, D.A.; Svoboda, S.J.; Hinton, R.Y.; Milzman, D.P. Incidence of knee injuries on artificial turf versus natural grass in national collegiate athletic association american football: 2004-2005 through 2013-2014 seasons. Am. J. Sports Med. 2019, 47, 1294-1301. [CrossRef]

41. Ferris, D.P.; Louie, M.; Farley, C.T. Running in the real world: Adjusting leg stiffness for different surfaces. Proc. Biol. Sci. 1998, 265, 989-994. [CrossRef] [PubMed]

42. Nordin, A.D.; Dufek, J.S.; Mercer, J.A. Three-dimensional impact kinetics with foot-strike manipulations during running. J. Sport Health Sci. 2017, 6, 489-497. [CrossRef] [PubMed]

43. Gruber, A.H.; Edwards, W.B.; Hamill, J.; Derrick, T.R.; Boyer, K.A. A comparison of the ground reaction force frequency content during rearfoot and non-rearfoot running patterns. Gait Posture 2017, 56, 54-59. [CrossRef]

(C) 2020 by the authors. Licensee MDPI, Basel, Switzerland. This article is an open access article distributed under the terms and conditions of the Creative Commons Attribution (CC BY) license (http://creativecommons.org/licenses/by/4.0/). 